applications. Pediatr Radiol 1986;16:126-30.

7 Levin AR, Goldberg HL, Borer JS, Rothenberg LN, Nolan FA, Engle MA et al. Digital angiography in the paediatric patient with congenital heart
disease; comparison with standard methods. Circulation 1983;68:374-84.

8 Bogren HG, Bursch JH. Digital angiography in the diagnosis of congenital heart disease. Cardiovasc Intervent Radiol 1984;7:180-8.

9 Bellamy. GR, Yiannikas J, Detrano R, Simpfendorfer C, Salcedo EE. Detection of multivessel disease after myocardial infarction using intravenous stress digital subtraction angiography. Radiology 1986 161:685-9.

10 Detrano R, Yiannikas J, Simpfendorfer C, Hobbs RE, Salcedo EE. Exercise digital subtraction ventriculography for the detection of ischaemic wal motion abnormalities in patients without myocardial infarction. Br Heart $J$ 1986;56:131-7.

11 Goldberg HL, Moses JW, Fisher J, Tamari I, Borer JS. Diagnostic accuracy of coronary angiography utilizing computer-based digital subtraction methods: comparison to conventional cineangiography. Chest 1986;90: 793-7.

12 Gurley JC, Nissen SE, Booth DC, Harrison M, Grayburn P, Elion J, et al. Comparison of simultaneously performed digital and film-based angiography in assessment of coronary artery disease. Circulation 1988;78: $1411-20$.
13 Katritsis D, Lythall DA, Anderson MH, Cooper IC, Webb-Peploe MM. Assessment of coronary angioplasty by an automated digital angiographic

14 Ratib OM, Mankovich NJ. Quantitative coronary arteriography: design and validation. Radiology 1988;167:743-7.

15 Popma JJ, Eichhorn EJ, Dehmer GJ. In vivo assessment of a digital angiographic method to measure absolute coronary artery diameter. Am J Cardiol 1989;64:131-8.

16 Ikeda $H$, Koga Y, Utsu F, Toshima $H$. Quantitative evaluation of regional myocardial blood flow by videodensitometric analysis of digital subtraction coronary arteriography in humans. J Am Coll Cardiol 1986;8:809-16.

17 Lefree MT, Simon SB, Mancini J, Bates ER, Vogel RA. A comparison of $35 \mathrm{~mm}$ cine film and digital radiographic image recording: implications for quantitative coronary arteriography. Invest Radiol 1988;23:176-83.

18 Simons MA, Muskett AD, Kruger RA, Klausner SC, Burton NA, Nelson JA. Quantitative digital subtraction coronary angiography using videodensitometry: an in vivo analysis. Invest Radiol 1988;23:98-106.

19 Pepine CJ. The cardiac catheterization laboratory-1990. Am J Cardiol 1990;66:37F-40F

20 Tobis J, Henry W, Nalcioglu O. Cardiac digital angiography. In: Brundage BH, ed. Comparative cardiac imaging. Rockville: Aspen, 1990:47-63.

\title{
PLANTS IN CARDIOLOGY
}

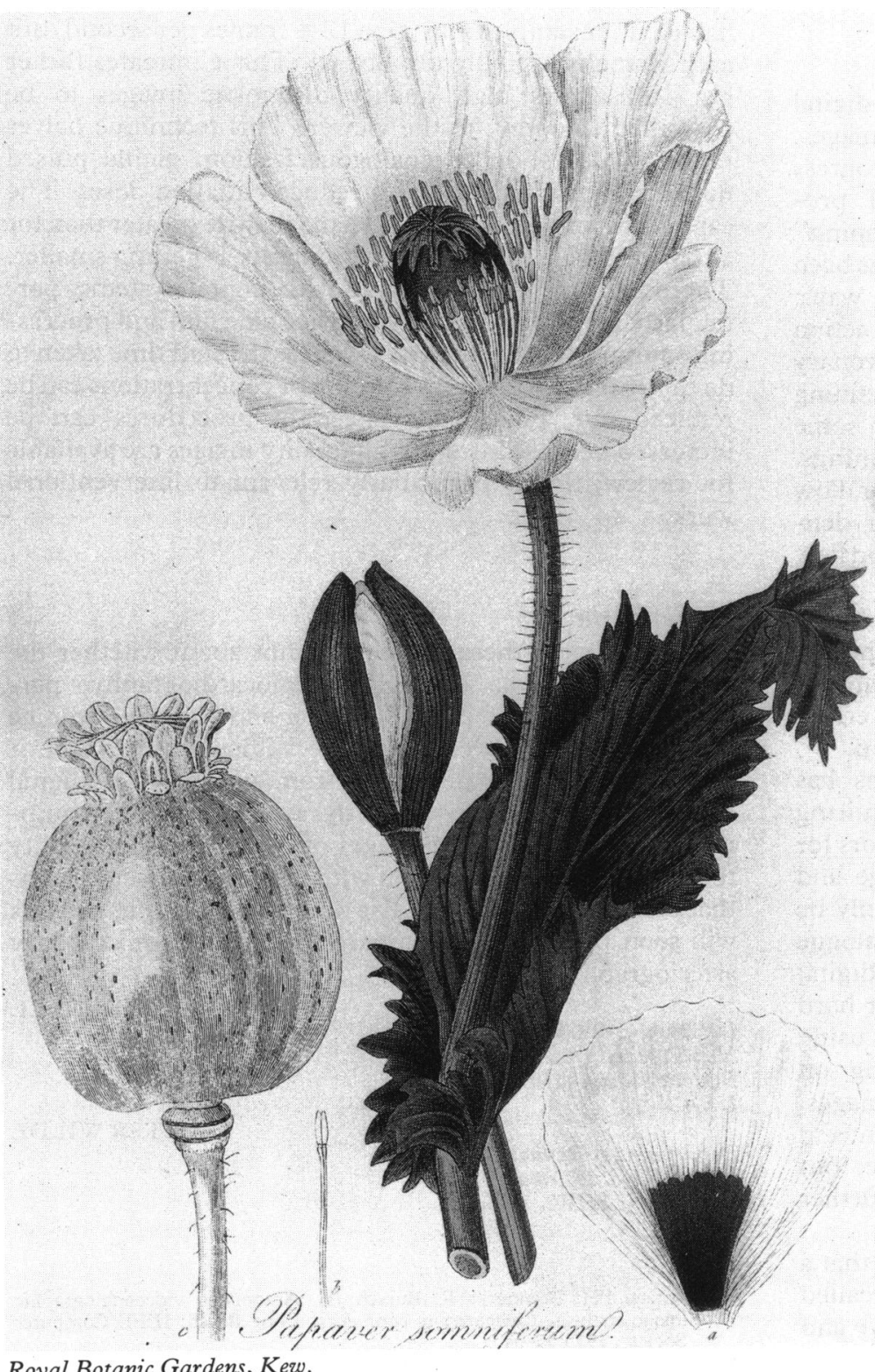

Royal Botanic Gardens, Kew.

Papaver somniferum $\mathrm{L}$. Stephenson J, Churchill J M. Medical botany. London: 1836, volume 3, plate 159.
When the unripe seed capsule of the opium poppy Papaver somniferum (Papaveraceae) is incised a milky fluid exudes. The dried juice, opium (from the Greek, opos, juice), has been used medicinally for over 5000 years. The 25 or so alkaloids of opium belong to two distinct chemical classes with quite different actions. Morphine and codeine belong to the phenanthrene class. Papaverine, which accounts for only $1 \%$ of the alkaloids, is in the benzylisoquinoline class and was isolated in 1848. But its lack of analgesic activity inhibited pharmacological investigation until 1917 when David Macht initiated this at Johns Hopkins Medical School. Because it relaxes smooth muscle it is a good vasodilator; in cardiac muscle it depresses conduction and prevents chloroform induced ventricular fibrillation. But PaulD White found it to be of little use in angina or hypertension and it was tried without success in cardiac arrhythmias. Nevertheless, papaverine and its synthetic analogues were popular as antispasmodic drugs for gastrointestinal and genitourinary ailments and in 1937 the German pharmaceutical firm Knoll asked their chemist, Ferdinand Dengel, to synthesise it. He worked on the compound for over 20 years and in May 1959 he produced an analogue, D365 (D for Dengel), which was soon shown to be pharmacologically much more active than other analogues or other similar drugs. Unlike other vasodilators it had negative inotropic and chronotropic effects. It was iproveratril, later to be called verapamil, and was marketed as Isoptin. Because it was thought to be a $\beta$ blocker clinical trials in angina began in 1961 . Fleckenstein's study of verapamil started in 1963 and led to his seminal discovery of calcium antagonism as its mode of action. In 1972 Schamroth, Krikler, and Garrett (British Medical Journal 1972;i:660-2) were the first to link the clinical action of verapamil in terminating arrhythmias with Fleckenstein's concept of calcium channel blockade.

Morphine, still pre-eminent for pain relief, was formerly valuable in acute left ventricular failure, and in 1942 Crighton Bramwell and J T King said, "morphine acts as a specific and what is more it is the only drug which is effective."

Papaver somniferum originated in the western Mediterranean and is cultivated chiefly in Asia and Tasmania. Its seed is free of opium and is used on bread. The poppy family, Papaveraceae, has 23 genera and 210 species, mostly in the northern hemisphere. None of its other species has alkaloids that are either better or different from those in the opium poppy.

A HOLLMAN 